\title{
Unused Meropenem Drug as Corrosion Inhibitor for Copper in Acidic Medium; Experimental and Theoretical Studies
}

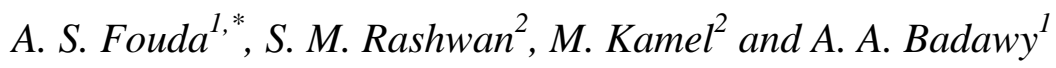 \\ ${ }^{1}$ Department of Chemistry, Faculty of Science, El-Mansoura University, El-Mansoura-35516, Egypt \\ ${ }^{2}$ Department of Chemistry, Faculty of Science, Suez Canal University, Ismailia, Egypt \\ "E-mail: asfouda@hotmail.com
}

doi: $10.20964 / 2016.11 .36$

Received: 25 May 2016 / Accepted: 5 September 2016 / Published: 10 October 2016

\begin{abstract}
Inhibitive and adsorption properties of unused meropenem drug for the corrosion of $\mathrm{Cu}$ in one molar $\mathrm{HNO}_{3}$ solution have been done by utilized (EIS), tafel polarization and (EFM) techniques as well as mass reduction methods of monitoring corrosion. The Effect of temperature was investigated at temperature range $\left(25-45^{\circ} \mathrm{C}\right)$. The obtained results indicated that the examined drug is an excellent inhibitor in $1 \mathrm{M} \mathrm{HNO}_{3}$ and its efficiency equalize to $98.7 \%$ at $300 \mathrm{ppm}$. The inhibition efficiency percent (\% IE) improvements with raising the drug dose while it lowering with raising the temperature of solution. The polarization data indicated that this drug play as mixed inhibitor type. The adsorption of the drug on the $\mathrm{Cu}$ surface follows the Temkin isotherm. Thermodynamic parameters have been calculated and discussed.
\end{abstract}

Keywords: Corrosion inhibition, Nitric acid, Copper, Unused meropenem drug

\section{$\underline{\text { FULL TEXT }}$}

(C) 2016 The Authors. Published by ESG (www.electrochemsci.org). This article is an open access article distributed under the terms and conditions of the Creative Commons Attribution license (http://creativecommons.org/licenses/by/4.0/). 